\title{
Clinical aspects of trace elements: Zinc in human nutrition - Assessment of zinc status
}

\author{
MiCHELle M PLUHATOR MSc, AlAN BR THOMSON MD PhD FRCPC FACP FRS FACC, RiCHARD N FEDORAK MD FRCPC
}

MM Pluhator, ABR Thomson, RN FEDORAK. Clinical aspects of trace elements: Zinc in human nutrition Assessment of zinc status. Can J Gastroenterol 1996; $10(1): 37-42$. Because the limiting and vulnerable zinc pool has not been identified, it becomes a challenge to determine which of the many zinc pools is most susceptible to deficiency. As a consequence, defining and assessing zinc status in the individual patient is a somewhat uncertain process. Laboratory analysis of zinc status is difficult because no single biochemical criterion can reliably reflect zinc body stores. Many indexes have been examined in the hopes of discovering a method for the assessment of zinc nutriture. None of the methods currently used can be wholeheartedly recommended because they are fraught with problems that affect their use and interpretation. However, these methods remain in use for clinical and research purposes, though their benefits and drawbacks must always be acknowledged. Until an acceptable method of analysis is discovered, clinicians must rely for confirmation of zinc deficiency on a process of supplementing with zinc and observing the patient's response. The main indexes (plasma/serum, erythrocyte, leukocyte, neutrophil, urine, hair and salivary zinc levels, taste acuity and oral zinc tolerance tests, and measurement of metallothionein levels) are reviewed. Measurement of plasma or erythrocyte metallothionein levels shows promise as a future tool for the accurate determination of zinc status.

Key Words: Deficiency, Nutrition, Toxicity, Zinc

\section{Aspects cliniques des éléments traces: Le statut du zinc dans l'alimentation humaine}

RÉSUMÉ : Compte tenu de notre relative ignorance des limites et de la vulnérabilité des réserves de zinc, il est difficile de déterminer lesquelles parmi les réserves de zinc de l'organisme sont les plus susceptibles de présenter un déficit. C'est pourquoi l'établissement du statut du zinc chez un patient ne saurait être pour l'instant qu'approximatif. On peut difficilement recourir aux analyses de laboratoire pour mesurer le zinc puisqu'aucun critère biochimique ne peut refléter avec justesse le taux de zinc. Aucune des méthodes actuellement employée ne peut être incontestablement recommandée parce qu'elles comportent toutes des lacunes qui nuisent à leur utilisation et à leur interprétation. Ces méthodes demeurent toutefois en usage à des fins cliniques et expérimentales, bien qu'il ne faille jamais mésestimer leurs avantages ni leurs inconvénients. Tant qu'une méthode d'analyse acceptable n'aura pas été découverte, les cliniciens doivent se rabattre sur l'administration de suppléments de zinc et sur l'observation de l'évolution du patient pour confirmer a posteriori qu'il y avait déficit en zinc. Les principaux indices (taux de zinc dans le plasma et le sérum, dans les érythrocytes, les leucocytes, les neutrophiles, l'urine, les cheveux, acuité gustative et tests oraux de tolérance au zinc, et mesure des taux de métallothionéine) sont passés en revue. La mesure des taux de métallothionéine du plasma ou des érythrocytes recèle la promesse d'un outil valable pour la mesure exacte des taux de zinc.

Division of Gastroenterology, Department of Medicine, University of Alberta, Edmonton, Alberta

Correspondence: Dr RN Fedorak, Division of Gastroenterology, Department of Medicine, University of Alberta, 519 Robert Newton Research Building, Edmonton, Alberta T6G 2C2. Telephone 403-492-6941, fax 403-492-3744

Received for publication August 16, 1994. Accepted January 23, 1995 
T his review is the fourth of a five-part series that examines zinc in terms of its biochemistry and physiology, metabolism, dietary requirements, nutritional assessment, and states of excess and deficiency.

Few research groups have attempted to classify what constitutes zinc deficiency for diagnostic purposes. However, Baer and King (1) suggested that the development of zinc deficiency can be divided into four stages based on changes in urinary zinc excretion and plasma zinc concentration, in addition to the development of clinical signs and symptoms (Table 1) (2). These stages were defined after a 10- to 11week zinc depletion-repletion study in healthy men. During stage I, plasma and urinary zinc levels both decline, but urinary zinc falls to a low level $(<2.3 \mu \mathrm{mol} / 24 \mathrm{~h})$ some time before plasma zinc is reduced to less than $10.7 \mu \mathrm{mol} / \mathrm{L}$. This discrepancy suggests that renal adjustments aimed at conserving tissue zinc occur early on in depletion. If an individual's initial zinc status is marginal, the adjustment can occur within seven days. During stage II, urinary zinc levels fall to less than $1.5 \mu \mathrm{mol} / 24 \mathrm{~h}$ and plasma zinc is reduced to subnormal levels, ie, 7.7 to $10.7 \mu \mathrm{mol} / \mathrm{L}$. In stage III, no further reduction in urinary zinc is seen, but plasma zinc levels are reduced to as low as $3.8 \mu \mathrm{mol} / \mathrm{L}$. At this point plasma zinc may still be distributed to tissues in order to maintain functions for which zinc is essential. In stage IV no further reductions in urinary and plasma zinc are observed. However, clinical signs of zinc deficiency become evident. These stages are early responses to acute zinc deficiency. Responses to marginal zinc intake or to a chronic state of zinc depletion may be quite different. Such a classification system may be useful to identify those who are zinc-deficient because of inadequate dietary zinc intake. Its simplicity may make it a valuable tool for population-based surveys of nutritional status. However, this classification system may be ineffectual in identifying all cases of zinc deficiency because zinc deficiency can also occur in the presence of hyperzincuria. Additionally, certain disease states may confound adequate classification. Such a classification system may, thus, only be beneficial for evaluating the zinc status of generally healthy individuals.

Ideally, the diagnosis of zinc deficiency should include metabolic balance and radioisotope turnover studies (3). These are not feasible in medical practice, so direct analysis of zinc in plasma/serum, red cells, leukocytes, urine and/or hair is generally used (Table 2 ). The best way to confirm zinc deficiency is still to supplement with zinc and observe the patient's response (4).

\section{ASSESSMENT OF ZINC STATUS: URINARY ZINC}

Urinary zinc excretion levels have been proposed as an index of zinc nutriture. Prasad and Cossack (5) suggest that a typical case of human zinc deficiency will show a urinary zinc loss of less than 2 SDs below the normal mean. Despite the supposed diagnostic significance of low urinary zinc excretion, however, many zinc deficiency conditions coexist with excessive urinary zinc excretion. In such situations, increased urinary excretion of zinc has been implicated in the
TABLE 1

Clinical values for diagnosis of zinc deficiency

\begin{tabular}{|c|c|c|}
\hline Test & Normal value & $\begin{array}{l}\text { Cut-off for diagnosis of } \\
\text { zinc deficiency }\end{array}$ \\
\hline Urinary zinc (24 h) & $\begin{array}{c}4.6 \text { to } 9.2 \\
\mu \mathrm{mol} / \text { day }^{*}\end{array}$ & $\begin{array}{c}\text { Stage I }<2.3 \mu \mathrm{mol} / \text { day }^{\dagger} \\
\text { Stage II }<1.5 \mu \mathrm{mol} / \text { day } \\
\text { Stage III }<1.5 \mu \mathrm{mol} / \text { day } \\
\text { Stage IV }<1.5 \mu \mathrm{mol} / \text { day } \\
\text { (clinical symptoms) }\end{array}$ \\
\hline Hair zinc & $\begin{array}{l}1.54 \text { to } 4.3 \\
\mu \mathrm{mol} / \mathrm{day}^{\ddagger}\end{array}$ & $<1.07 \mu \mathrm{mol} / \mathrm{g}^{\ddagger}$ \\
\hline Plasma/serum zinc & $\begin{array}{c}10.7 \text { to } 23.0 \\
\mu \mathrm{mol} / \mathrm{L}^{\ddagger}\end{array}$ & $<10.7 \mu \mathrm{mol} / \mathrm{L}^{\ddagger}$ \\
\hline
\end{tabular}

${ }^{*}$ From reference $8 ;{ }^{\dagger}$ Based on reference $1{ }^{\ddagger}{ }^{\ddagger}$ Based on reference 2

\section{TABLE 2}

\section{Methods for assessment of zinc status}

\begin{tabular}{l}
24 h urine zinc excretion \\
Hair zinc content \\
Salivary zinc concentration \\
Taste acuity \\
Blood analyses \\
Plasma/serum zinc concentration \\
Erythrocyte zinc content \\
Leukocyte zinc content \\
Oral zinc tolerance test \\
Metallothionein \\
\hline
\end{tabular}

pathogenesis of zinc deficiency (6). Among the conditions in which both hypozincemia and hyperzincuria have been reported are sickle cell anemia and cirrhosis of the liver (7). Hyperzincuria is also present after injury, burns, acute starvation, certain renal diseases and some infections $(6,7)$. Hence, the measurement of zinc in urine is only helpful for diagnosing zinc deficiency in apparently healthy persons $(1,8)$. In disease-free individuals, a decreased urinary zinc excretion occurs with the development of zinc deficiency. Nishi et al (9) have suggested that low urinary zinc may be a valid indicator of zinc deficiency, especially when the urinary level remains low after an oral zinc load. Levels of zinc in the urine usually range from 0.3 to $0.6 \mathrm{mg} / \mathrm{day}$ (8). In general, $24 \mathrm{~h}$ urine collections are preferable to 'spot' samples because diurnal variation in urinary zinc excretion exists (8). Major disadvantages of the $24 \mathrm{~h}$ urine collection for trace mineral determinations include that this method is time-consuming, cumbersome and highly susceptible to exogenous metal contamination (6).

\section{ASSESSMENT OF ZINC STATUS: HAIR ZINC}

The available evidence suggests that low zinc concentrations in hair samples collected during childhood probably reflect a chronic suboptimal zinc status in the absence of the confounding effect of severe protein-energy malnutrition $(10,11)$. Hair zinc analysis cannot be used in cases of severe malnutrition and/or severe zinc deficiency when the rate of 
hair growth is diminished. In such cases, hair zinc concentrations may be normal or even high (8).

Low hair zinc concentrations were reported in the first documented cases of human zinc deficiency, which involved young adult male dwarfs from the Middle East. Low hair zinc concentrations are also displayed by subjects with impaired taste acuity and/or those with low growth percentiles, two clinical features of marginal zinc deficiency in childhood $(10,11)$. In most cases of suboptimal zinc status, hair concentrations increase in response to zinc supplementation. Inconsistencies in results can arise from variations in the supplemental dose and length of supplementation period, as well as from confounding seasonal effects on zinc hair concentration (8).

Standardized protocols for sampling, washing and analyzing hair are essential in all studies. Hair zinc concentrations vary with hair colour, treatments, season, sex, age, anatomical site of sampling and rate of hair growth (8). The effects of these possible confounding factors must be considered when interpreting the zinc concentrations of hair.

Many investigators have not found positive correlations between the zinc content of hair and serum/plasma zinc concentrations after conducting cross-sectional or relatively short term longitudinal zinc depletion or zinc supplementation studies. This is not surprising. The zinc content of the hair shaft reflects the quantity of zinc available to hair follicles at an earlier time. Positive correlations between hair zinc concentrations and other biochemical indexes are only observed in cases of chronic zinc deficiency. It is unfortunate that few long term zinc depletion human studies have simultaneously examined hair, serum and tissue zinc concentrations.

Clinical signs of marginal zinc deficiency in childhood are usually associated with hair zinc concentrations of less than $1.07 \mu \mathrm{mol} / \mathrm{g}$ (11) (Table 1). This value is often used as the cut-off for hair zinc concentrations suggestive of suboptimal zinc status in children. The validity of hair zinc level as an index of chronic suboptimal zinc status in adults remains uncertain.

\section{ASSESSMENT OF ZINC STATUS: SALIVARY ZINC}

Zinc appears to be a component of gustin, an essential protein involved in taste acuity. It has been suggested that gustin deficiency mediates the impairment of taste in zincdeficient individuals (6). Zinc concentrations in mixed saliva, parotid saliva, salivary sediment and salivary supernatant have all been investigated, but their use as indexes of zinc status is uncertain (1). No changes in salivary zinc concentration were reported in the case of experimentally induced human zinc deficiency (1) or adults supplemented with zinc (12).

Although the collection of saliva samples is quick and relatively noninvasive, the rate of flow and stimulation of saliva production is difficult to control, and diurnal variation in zinc levels may occur $(6,13)$. These problems, and the contradictory results observed, limit the use of salivary zinc as an index of zinc status (8).
ASSESSMENT OF ZINC STATUS: TASTE ACUITY

Diminished taste acuity (hypogeusia) is one of the features of marginal zinc deficiency, and it has been used as a functional index of zinc status. Several methods for testing taste acuity have been used (14), but, for all methods, tests should be performed midmorning, at least $2 \mathrm{~h}$ after a meal, and by the same person on each occasion (8). The three drop stimulus technique consists of presenting a single drop of each test solution and two drops of distilled water, in random order, onto the anterior two-thirds of the tongue. Test solutions of the four taste qualities are used. Evaluation of taste acuity is based on the detection and recognition thresholds for each taste quality. The detection threshold is defined as the lowest concentration at which a taste can just be detected and the recognition threshold is the lowest concentration at which the quality of the taste stimulus can be recognized (14). An alternative technique assesses only recognition thresholds, a test said to be suited to young children (8). Using recognition thresholds for only one taste quality (salt) minimizes potential problems with short attention spans and distractions. Individuals rinse a small amount (10 $\mathrm{mL}$ ) of each of a 10, 15, 20 and $25 \mathrm{mmol} / \mathrm{L}$ sodium chloride solution around in their mouths, expectorate it and then try to identify whether the sample is salty or plain water. Salt solutions of increasing or decreasing concentration are used until the individual correctly identifies salt at one concentration and fails to do so at the next lower concentration. At the moment, few conclusions can be drawn about the relationship between zinc deficiency and taste acuity. Perhaps other aspects of the gustatory sense, such as taste preference, will prove to be more reproducibly related to zinc nutriture than the taste acuity threshold.

ASSESSMENT OF ZINC STATUS: BLOOD ZINC Plasma/serum zinc concentrations: Plasma zinc testing has been criticized as a measurement of zinc status because it does not reflect reductions in dietary zinc intake or changes in whole body zinc (15). Since only minimal changes in whole body zinc develop during zinc depletion, changes in plasma levels cannot be linked to whole body zinc (15). In addition, plasma zinc levels seem to decline only when dietary intake is so low that homeostasis cannot be maintained without the use of some zinc from the exchangeable pool, of which plasma zinc is a component. Thus, plasma zinc is thought to be a useful indicator of the size of the exchangeable zinc pool. The reduction in plasma zinc mirrors the loss of zinc from bone and liver, and indicates an increased risk of the development of metabolic and clinical signs of zinc deficiency (15). Further research is needed to delineate more precisely the threshold at which use of the exchangeable pool of zinc begins (15).

The extent to which the size and activity of the exchangeable pool of zinc is influenced by age, sex, body size, body composition and long term dietary zinc intake is not yet known (15). Plasma zinc concentration is also sensitive to other metabolic changes. In times of acute infection or inflammation, serum/plasma zinc values are artificially low because zinc is redistributed from the plasma to the liver (8). 
This redistribution is mediated by a leukocytic endogenous mediator that is released by phagocytizing cells during the acute phase response $(6,8)$. Other confounding factors include chronic disease states associated with hypoalbuminemia, such as alcoholic cirrhosis and protein-energy malnutrition (6). Plasma zinc levels may be low in such situations because albumin is low, and there is thus a reduced plasma concentration of zinc binding sites (6).

Considerable clinical data suggest that stress, in a variety of forms, alters the kinetics of zinc metabolism to produce a depressed plasma zinc content (16). The effect is not specific, but may occur with any acute disease (16). A mechanism involving adrenocorticotropic hormone release and zinc reduction in an albumin-like fraction of plasma has been proposed.

Steroids in many forms will depress circulating concentrations of zinc. Such steroids include exogenous cortical steroids, oral contraceptives and the endogenous gonadal hormones released during pregnancy (6). The fall in plasma or serum zinc concentrations starts very early during pregnancy and continues until about 36 weeks (17). This fall is likely the result of a number of factors including the expansion of plasma volume, the hypoalbuminemia of pregnancy, a reduced affinity of albumin for zinc (18) and the redistribution of zinc induced by estrogen, cortisol and other endocrine changes.

In a study of diurnal serum zinc variability in healthy adult males, a ' $U$ ' shaped curve was derived; from the results a peak zinc level occurred at 09:30 and a midtrough occurred at 18:00. The peak-trough difference was $19 \mu \mathrm{g} / \mathrm{dL}$ (19). In addition, a high correlation was found between serum zinc and calcium rhythms, a finding that suggests a shared mode of regulation. Parathyroid hormone and calcitonin administration have produced redistributions of tissue zinc in experimental animals (19). Therefore, calcium-regulating hormones directly or indirectly affect zinc metabolism. Declines in serum zinc levels were reported during the morning for fasting subjects, and small increases of serum zinc have been noted 30 to 90 mins after meals (19). The circadian zinc rhythm is affected, but not determined, by food quantity, type and timing of intake. Short term fasting has been reported to elevate plasma zinc concentrations (6). It has been suggested that the differential between fasting and postprandial plasma zinc levels may be of greater diagnostic value than the fasting level alone because the differential appears to be exaggerated for a low zinc diet (1).

The fall in plasma zinc seen with all of the aforementioned conditions except fasting may be the result of zinc redistribution to other tissues in response to a metabolic need, rather the indication of a change in zinc status $(15,20)$. Thus, plasma zinc has been regarded as an unreliable indicator of zinc deficiency and zinc status. Plasma zinc can only be useful as a specific indicator of zinc status if the effects of changes in zinc status and other metabolic conditions can be differentiated (15). If serum/plasma zinc levels are to be measured and employed as a measurement of zinc status, standardization of testing is necessary. The measurements must be taken at the same time and under the same conditions (eg, fasting state) on each occasion. Further study is needed to establish norms under a variety of physiological and dietary conditions, as well as to establish the feasibility of such an approach in the detection of marginal zinc statuses.

The cut-off generally used to assess the risk of zinc deficiency for both plasma and serum values is less than 10.71 $\mu \mathrm{mol} / \mathrm{L}$, a value approximately $2 \mathrm{SDs}$ below the adult mean (8) (Table 1). This value may only be appropriate for morning fasting blood samples. For nonfasting morning and for afternoon samples, cut-off points of less than $9.95 \mu \mathrm{mol} / \mathrm{L}$ and less than $9.18 \mu \mathrm{mol} / \mathrm{L}$, respectively, have been recommended (8).

Erythrocyte zinc concentrations: Erythrocytes have rarely been used as biopsy material to assess zinc status because they are difficult to analyze and provide ambiguous responses during zinc depletion-repletion studies (1). The half-life of erythrocytes is quite long (120 days) and the zinc concentrations of erythrocytes will not reflect recent changes in bodily zinc stores. For example, one human zinc depletion study found only a $21 \%$ decline in erythrocyte zinc concentrations after subjects had been on a low zinc diet for as long as 90 days (21). Reduced erythrocyte zinc has been reported in children with protein-energy malnutrition and in adults with sickle cell disease (6). Much remains to be learned about the metabolism of zinc in red cells, its dependence on circulating zinc levels and its reflection of zinc nutriture.

Leukocyte and neutrophil zinc concentrations: Leukocytes contain up to 25 times more zinc than erythrocytes. Early studies suggested that leukocyte zinc was a more reliable index of zinc status than erythrocyte or plasma zinc (22) and that it reflected levels of soft tissue zinc (8). Neutrophils have a short half-life and a high zinc content. In a human zinc depletion study by Prasad and Cossack (5), neutrophil zinc concentrations, but not concentrations of plasma zinc, decreased significantly after only four weeks of a marginally zincdeficient diet. Neutrophil zinc concentrations were also low in zinc-deficient sickle cell anemia patients and correlated with other biochemical indexes of zinc status (5). The main drawback in the use of white blood cells is the need to separate and isolate specific cell types (6). It is also crucial that cell suspensions be free from erythrocytes and platelets because both have a relatively high zinc content (8). In view of the methodological problems, the validity of leukocyte and neutrophil zinc as indexes of zinc status remains uncertain. In addition, relatively large volumes of blood are required, and the use of these indexes is limited for infants and children (8).

Oral zinc tolerance test: A zinc tolerance test, also referred to as a plasma appearance test, measures the increase in plasma zinc from the fasting level caused by oral ingestion of a pharmacological dose of zinc. Generally a fixed dose of 25 or $50 \mathrm{mg}$ zinc as zinc acetate is used, regardless of body weight. It may be preferable to give the dose on a per kilogram body weight basis (23). Samples of plasma are collected after a $12 \mathrm{~h}$ fast and at every hour postdose for $5 \mathrm{~h}$. Individuals must not 
eat or drink anything during the postdose period. The test is used as a measure of zinc status with the assumption that it reflects overall zinc absorption, the rate of which increases in times of zinc deficiency. Variable results among individuals in any group have been noted, making the test more useful when each person serves as his or her own control (24). The oral zinc tolerance test has also been used to assess the effects of different foods, meals, vitamin and mineral supplements (25), disease processes and medications on zinc absorption (24). The usefulness of the oral zinc tolerance test may be limited by the current use of pharmacological doses of zinc. Such doses may be handled differently from dietary zinc by the gastrointestinal tract (8).

Metallothionein: Metallothionein may be one key to the diagnosis of tissue zinc redistribution (15). This low molecular weight protein is found in variable amounts in most tissues, but is particularly concentrated in the liver, pancreas, kidney and intestinal mucosa. Under normal physiological conditions, metallothionein binds zinc and copper (15). Tissue metallothionein concentrations are usually proportional to zinc levels (ie, they decline to nondetectable levels in zincdeficient animals and increase following parenteral or dietary administration of zinc) (15). Dietary and liver zinc are closely associated with metallothionein; as dietary zinc concentrations increase, metallothionein synthesis is induced, and most of the additional zinc in the liver is bound to metallothionein (15). Metallothionein can also be detected in the plasma and erythrocytes, and both are sensitive to dietary zinc intake. Plasma metallothionein reflects changes in hepatic metallothionein concentration but erythrocyte metallothionein does not (15). Increases in hepatic metallothionein in response to stress, inflammation or hormonal changes will cause analogous changes in plasma metallothionein levels. It is important to note, however, that when an infection or other stress exists, the rise in plasma metallothionein normally seen in the zinc-replete animal does not occur if the subject is zinc-deficient (20). Both plasma zinc and plasma metallothionein levels should clearly indicate whether an individual is zinc-deficient $(15,20)$.

Preliminary studies on the reaction of erythrocyte metallothionein to changes in dietary zinc have been encouraging. Measurements of the erythrocyte metallothionein fraction have an advantage over other measurements because these results are not responsive to stress $(15,20)$. A REFERENCES

1. Baer MT, King JC. Tissue zinc levels and zinc excretion during experimental zinc depletion in young men. Am J Clin Nutr 1984;39:556-70.

2. Teitz NW, ed. Clinical Guide to Laboratory Tests, 2nd edn. Philadelphia: WB Saunders Company, 1990.

3. Peereboom JWC. General aspects of trace elements and health. Sci Total Environ 1985;42:1-27.

4. Golden MHN. Trace elements in human nutrition. Hum Nutr 1982;36:185-202.

5. Prasad AS, Cossack ZT. Neutrophil zinc: an indicator of zinc status in man. Trans Assoc Am Physicians 1982;95:165-76.

6. Solomons NW. On the assessment of zinc and copper nutriture in man. Am J Clin Nutr 1979;32:856-71.

7. Prasad AS. Clinical, biochemical and nutritional spectrum of zinc deficiency in human subjects: an update. Nutr Rev 1983;41:197-208.

8. Gibson RA. Assessment of trace element status. In: Principles of study by Thomas et al (26) confirmed the responsiveness of erythrocyte metallothionein to dietary zinc intake. Healthy males participated in a 90-day study that consisted of four phases: dietary zinc acclimation, treatment, depletion and supplementation. Because humans can adapt to varying zinc intakes by changing the rates of absorption and excretion of zinc, a major improvement of this study over a traditional depletion-repletion protocol was the use of dietary treatment preceding depletion.

Erythrocyte metallothionein concentrations were determined using a human metallothionein enzyme-linked immunosorbent assay. Thomas and colleagues (26) found it useful to identify zinc depletion. Used in evaluating change over time, erythrocyte metallothionein testing successfully distinguished between those whose zinc intakes were equal to the American Recommended Dietary Intake and those ingesting a level similar to that of populations at risk of moderate zinc deficiency. The change in erythrocyte metallothionein levels following a six-week low zinc diet suggests that this index would be useful in monitoring clinical zinc status over time (26).

Erythrocyte metallothionein may represent the much sought after step forward to a definite test for zinc deficiency, and it is thus possible that a much clearer understanding of the nature of zinc deficiency may develop soon. It is likely that the erythrocyte metallothionein assay will soon become established as a means to assess zinc status. Until then, however, the assessment of zinc status must rely on the clinician's ability to recognize historical and clinical data consistent with zinc deficiency, as well as his or her knowledge of the confounding factors that currently affect the measurement of multiple clinical parameters.

It appears that the most imperative need is for improved biochemical criteria, both for diagnostic purposes and to monitor dose/response relationships during studies of the functional requirements of zinc. Until such diagnostic measurements are developed, the simultaneous monitoring of changes in plasma/serum zinc and urinary zinc, with a consideration for the expression of clinical symptoms of zinc deficiency, must be relied upon. It is hoped that the measurement of plasma or erythrocyte metallothionein will impart a more accurate diagnostic tool to determine zinc status.

Nutritional Assessment. New York: Oxford University Press, 1990:511-76.

9. Nishi Y, Litshitz F, Bayne MA, Daum F, Silverberg M, Aiges H. Zinc status and its relation to growth retardation in children with chronic inflammatory bowel disease. Am J Clin Nutr 1980;33:2613-21.

10. Gibson RS, Smit-Vanderkooy PD, MacDonald AC, Goldman A, Ryan B, Berry M. A growth limiting mild zinc deficiency syndrome in some Southern Ontario boys with poor growth percentiles. Am J Clin Nutr 1989;49:1266-73.

11. Hambidge KM, Hambidge C, Jacobs M, Baum JD. Low levels of zinc in hair, anorexia, poor growth and hypogeusia in children. Pediatr Res 1972;6:868-74.

12. Krebs JM, Schneider VS, LeBlanc AD, Kuo MC, Spector E, Lane HW. Zinc and copper balances in healthy adult males. Am J Clin Nutr 1992;58:897-901. 


\section{Pluhator et al}

13. Warren DC, Lane HW, Mares M. Variability of zinc concentrations in human stimulated parotid saliva. Biol Trace Elem Res 1981;3:99-107.

14. Bartoshuk LM. The psycho-physics of taste. Am J Clin Nutr 1978;31:1068-77.

15. King JC. Assessment of zinc status. J Nutr 1990;120:1474-9.

16. Cousins RJ. Systemic transport of zinc. In: Zinc in Human Biology. London: Springer-Verlag, 1989:79-93.

17. Aggett PJ, Campbell DM, Page KR. The metabolism of trace elements in pregnancy. In: Chandra RK, ed. Trace Elements in Nutrition of Children - II. New York: Raven Press, 1991:27-48.

18. Aggett PJ. Trace elements in human pregnancy and lactation. In: Chandra RK, ed. Trace Elements in Nutrition of Children. New York: Raven Press, 1985:137-55.

19. Markowitz ME, Rosen JF, Mizruchi M. Circadian variations in serum zinc $(\mathrm{Zn})$ concentrations: correlation with blood ionized calcium, serum total calcium and phosphate in humans. Am J Clin Nutr 1985;41:689-96.

20. Golden BE. Zinc in cell division and tissue growth: physiological aspects. In: Mills CF, ed. Zinc in Human Biology. London: Springer-Verlag, 1989:119-28.

21. Buerk CA, Chandy ME, Pearson E, MacAuly A, Soroff HS. Zinc deficiency. Effect on healing and metabolism in man. Surg Forum 1973;24:101-3.

22. Prasad AS, Rabbani P, Abbasi A, Bowersox E, Fox MRS. Experimental zinc deficiency in humans. Ann Intern Med 1978;89:483-90.

23. Watson WS. Plasma zinc uptake and taste acuity. Am J Clin Nutr 1988;47:336.

24. Abu-Hamdan DK, Mahajan SK, Migdal SD, Prasad AS, McDonald FD. Zinc tolerance test in uremia. Ann Intern Med 1986;104:50-2.

25. Solomons NW. Factors affecting the bioavailability of zinc. J Am Diet Assoc 1982;80:115-21.

26. Thomas EA, Bailey LB, Kauwell GA, Lee D, Cousins RJ. Erythrocyte 


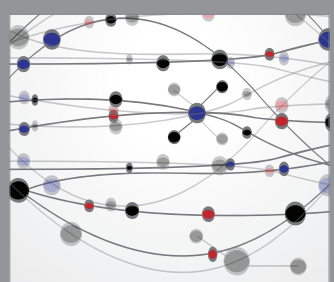

The Scientific World Journal
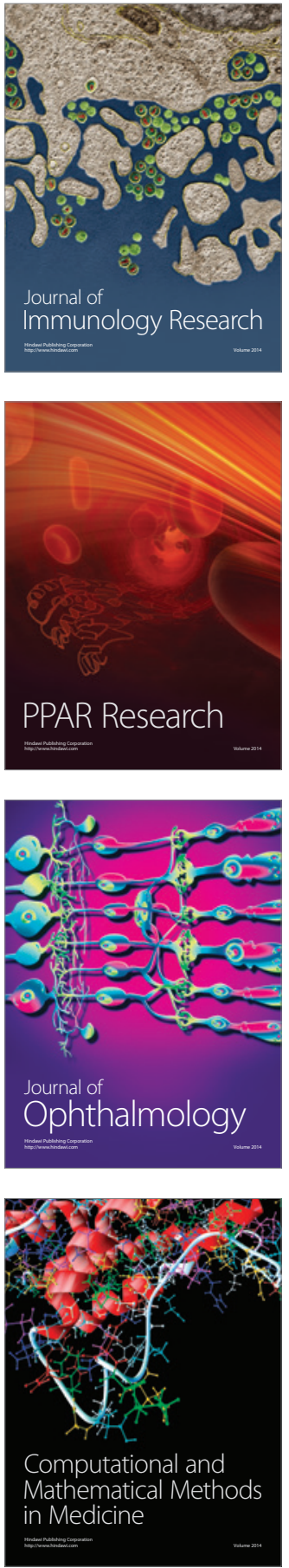

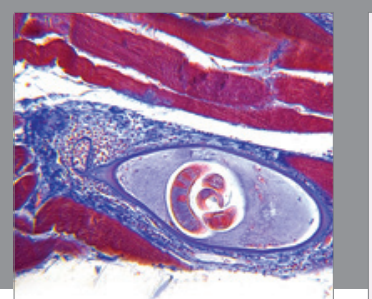

Gastroenterology Research and Practice

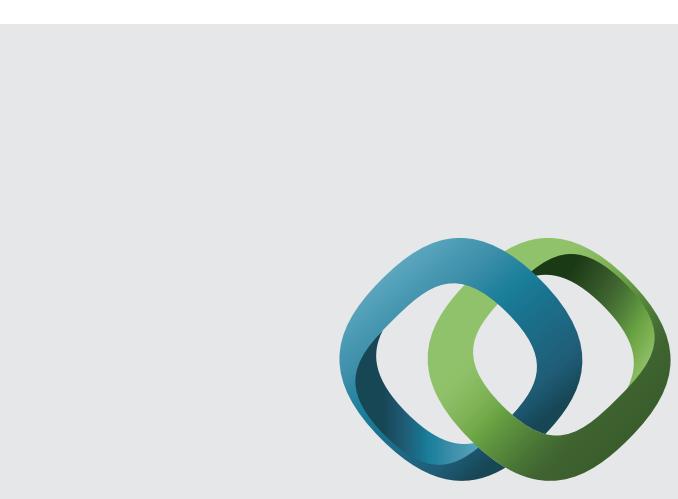

\section{Hindawi}

Submit your manuscripts at

http://www.hindawi.com
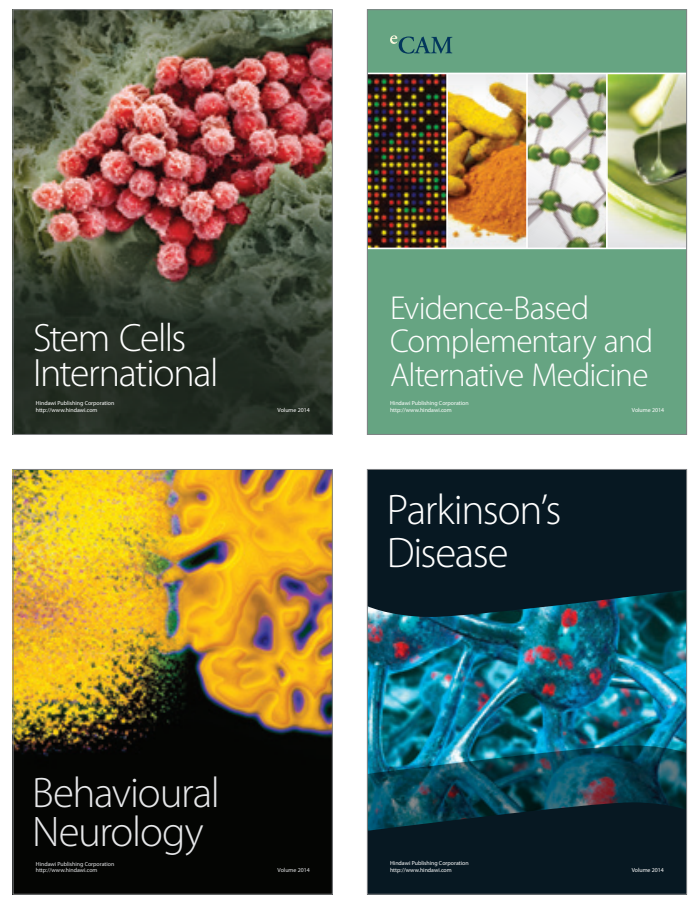
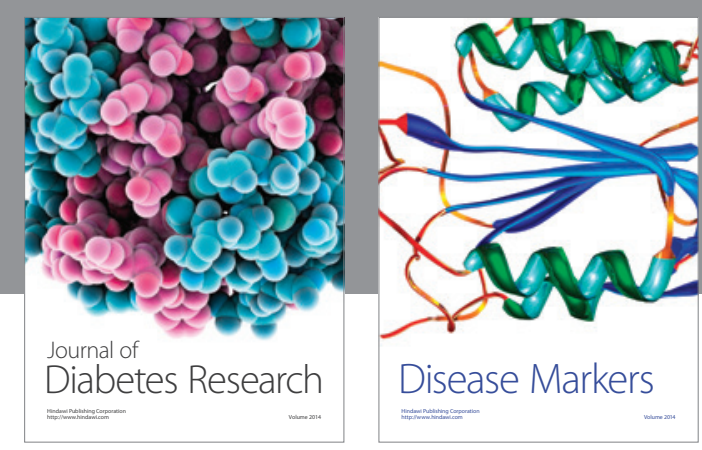

Disease Markers
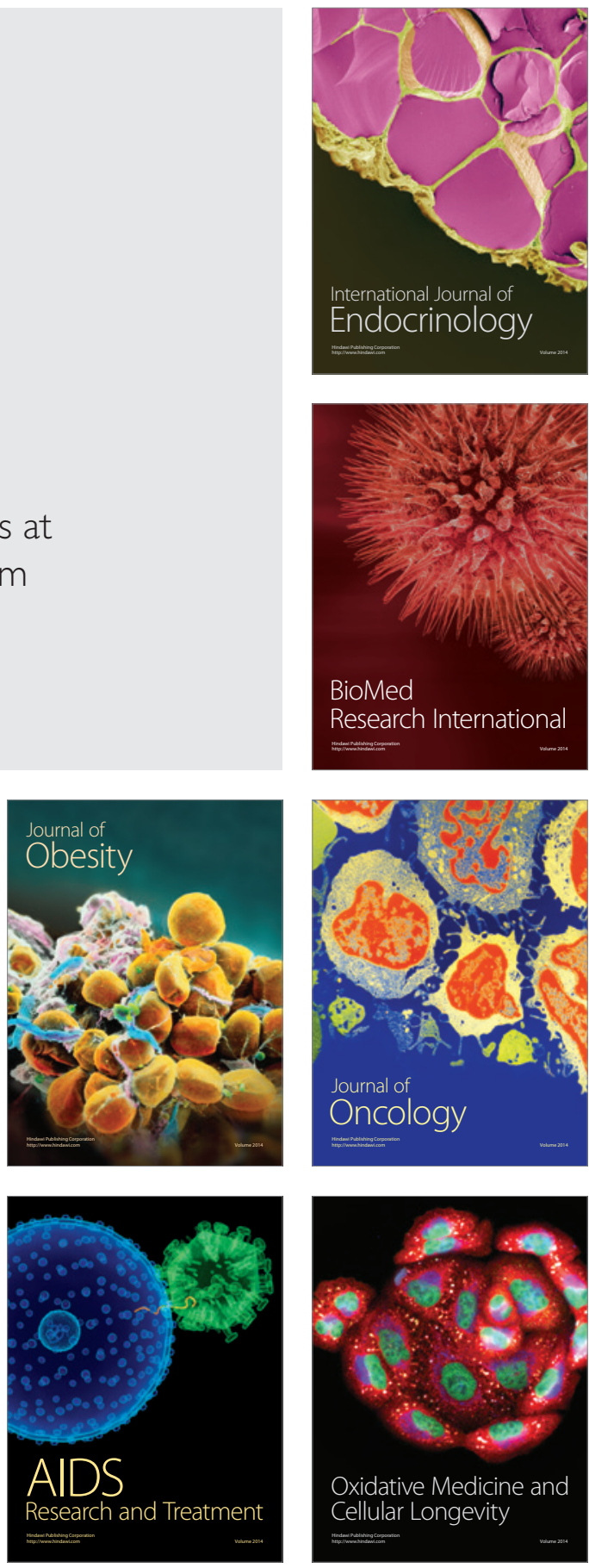